\title{
11 (Re)conceptualising poverty and informal employment
}

\author{
Michael Rogan and Paul Cichello
}

This chapter aims to address the dominant narrative that informal employment is comprised of low-paid and unproductive work. This is not to deny that working poverty is the reality for many informal workers or that, of the roughly 839 million working poor in the developing world who survive on less than $\$ 2 /$ day, about 80 per cent are informally employed (ILO 2016b). However, the poverty narrative ignores what this income provides daily to working individuals and families. It also reinforces the dualist conceptualisation of the informal economy as a backward sector which is uncoupled from the "modern" formal sector. The conventional poverty approach therefore frames the informal economy as a problem to be solved rather than as an important source of household income or a critical base of the modern economy.

A better understanding of the role of informal employment in actually reducing poverty - rather than perpetuating it - could influence a new generation of policies that recognise and support the role of earnings from informal employment in the households of the working poor. This is an important consideration since progress in reducing working poverty (that is, poverty among the employed), particularly in developing countries, has stalled over the past five years (ibid.). There will, therefore, come a point when addressing poverty in the informal economy will need to receive more attention from countries as they strive to meet their poverty reduction targets.

\section{The informal economy and working poverty in South Africa}

To explore the potential for measuring the link between informal employment and poverty reduction, we undertook a poverty decomposition analysis using household survey data from South Africa (Cichello and Rogan 2017). This method (Araar and Duclos 2009), based on Shapley values, estimates what the rate of poverty would have been without each type of income that the households receive (e.g., government transfers, labour market income, remittances, investments, etc.) ignoring any potentially endogenous responses from the household to that lost income.

South Africa is a middle-income country with a high level of inequality and roughly a third of the non-agricultural workforce in informal employment (ILO 
2018a). A cursory analysis of household income data as typically measured from income and expenditure surveys can be deceiving. Absolute levels of earnings simply reflect the fact that individual earnings and household incomes are often very low in the informal economy. Without contextualising the impact of these earnings, a first glance at the distribution of household income in South Africa shows that the vast majority ( 57 per cent) of all household income is attributed to "formal" earnings and relatively little income flows into households from government transfers and informal employment, 7 per cent and 9 per cent, respectively. The income from transfers, in the form of the government's social grant programme, is widely acknowledged to have impacted positively on child health and education, food security, and in reducing income poverty. In contrast, the income that is derived from employment in the informal economy is rarely recognised while some policy interventions, namely, the city of Johannesburg's removal of informal traders under 'Operation Clean Sweep' in 2013, have actively worked to suppress informal livelihoods.

When considering the impact of transfer income and earnings from informal employment on keeping households above one of the country's official poverty lines, we highlight three findings from the South African case study. First, while earnings from formal employment are still the single largest factor in reducing poverty, government transfers and earnings from informal employment are actually more important to poverty reduction, relative to their overall share of household income. For example, while only 9 per cent of household income comes from informal employment, 14 per cent of the household income that moves households above the poverty line is attributed to informal employment (Figure 11.1). This is the case for two reasons. First, the households that are closest to the poverty line are more likely to be earning income from the informal economy. Second, even though earnings from informal employment are often very low, they are often enough to move these households just above, or at least closer to, the poverty line. This is an important finding for policy-makers, because it highlights the role that earnings from the informal economy contribute both to households and to poverty reduction at the national level.

Second, there is substantial variation in poverty reduction within the informal economy. Figure 11.2 illustrates the ratio of poverty reduction to relative income in Rand for several types of informal employment in South Africa at the three official poverty lines. At all three poverty lines, the contribution of informal selfemployment to reducing poverty is similar to its contribution to total income (hence a ratio of approximately one). In contrast, income from formal employment contributes less to poverty reduction relative to its large contribution to total household income. At the lowest poverty threshold (also called the extreme poverty line), the contribution of income from formal employment is only about 66 per cent of its contribution to total income.

The incomes from several types of informal employees (both inside and outside of the informal sector) appear to be particularly effective in reducing poverty. The earnings of domestic workers, for example, constitute more than double (e.g., 2.5 times at the lowest poverty line) the amount in poverty 


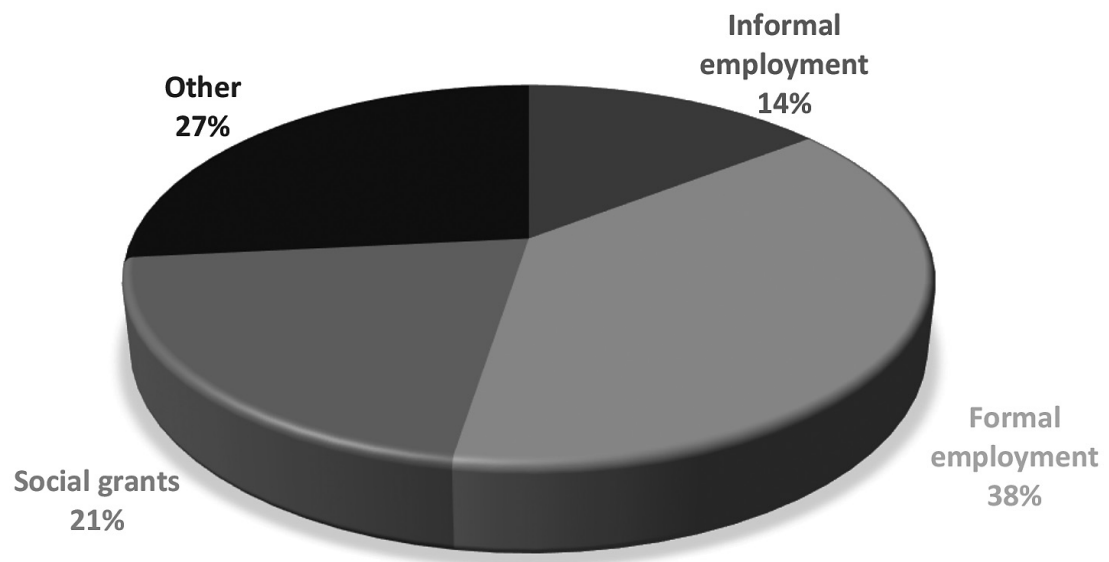

Figure 11.1 Contributions to poverty reduction by income source (Shapley poverty decompositions).

Source: Own calculations (Cichello and Rogan, 2017) from NIDS using the DASP module developed by Araar and Duclos (2007).

Notes

The data are weighted.

Income sources and poverty lines are expressed in monthly per capita terms (2010 prices, $\mathrm{z}=306)$.

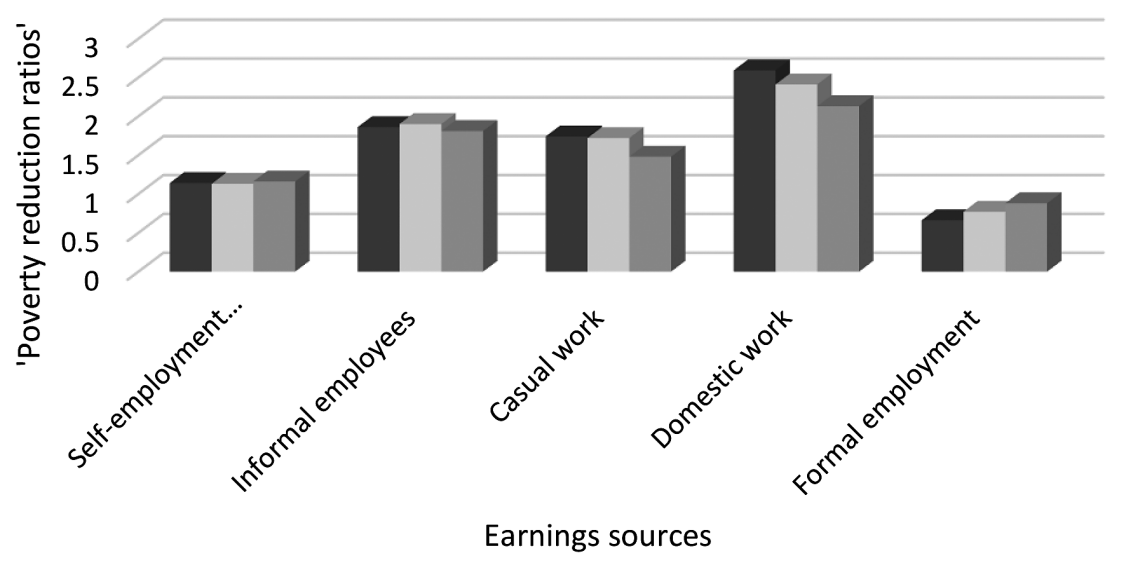

R307 R424 R594

Figure 11.2 Poverty reduction ratios by different categories of informal employment (Shapley poverty decompositions).

Source: Own calculations (Cichello and Rogan, 2017) from NIDS using the DASP module developed by Araar and Duclos (2007).

Notes:

The data are weighted.

Income sources and poverty lines are expressed in monthly per capita terms (in Rand, 2010 prices). 
reduction at all three poverty lines relative to their share of overall income. Similarly, the earnings of informal employees and casual workers are nearly twice as effective at reducing poverty as their contributions to total household income in South Africa would suggest.

Third, the 'per job' impact of informal jobs on overall poverty reduction is relatively high. In Figure 11.3, the estimated "per job" impact on poverty of earnings from informal employment, relative to the impact of a formal job is compared. Despite significantly lower incomes in the informal economy, the earnings of a typical self-employed worker in South Africa have 63 per cent of the poverty-reducing impact, at the extreme poverty line, compared with earnings from a formal sector job. Put differently, eliminating 100 informal selfemployment activities, as some government policies have sought to do in order to discourage "illegal trading", would drive as many individuals into extreme poverty as eliminating 63 formal jobs. It is precisely these types of stark comparisons that are made possible when the focus is switched to the contribution of informal employment to poverty reduction.

Informal employees and domestic workers have a "per job" impact on poverty reduction which is even closer to a formal job (81 per cent and 85 per cent, respectively). In other words, policies which endanger these jobs or reduce their earnings would be almost the same as eliminating formal jobs in terms of poverty reduction. So it is the ability of these types of employment, despite their low earnings and difficult working conditions, to keep households out of poverty that makes their contributions so significant.

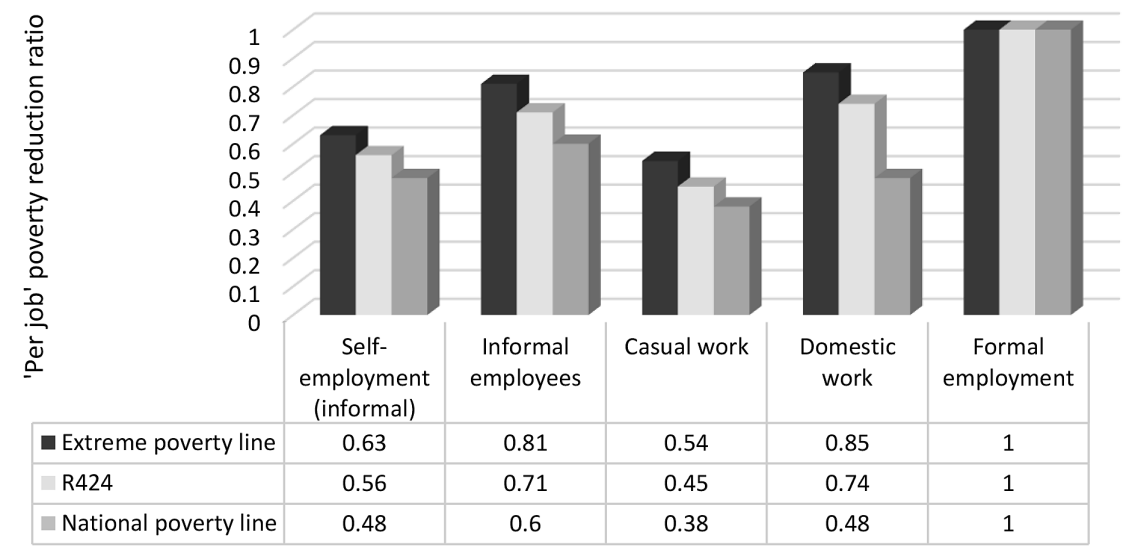

Figure 11.3 Relative 'per job' impact of earnings from informal employment on poverty reduction (Shapley poverty decompositions).

Source: Own calculations (Cichello and Rogan, 2017) from NIDS using the DASP module developed by Araar and Duclos (2007).

Notes:

The data are weighted.

Income sources and poverty lines are expressed in monthly per capita terms (Rand 2010 prices). 


\section{(Re)conceptualising poverty and informal employment}

One conclusion from the analysis of South African earnings data is that, if governments are serious about reducing working poverty in developing countries, then protecting the earnings and working conditions of workers in the informal economy should be a priority.

National poverty estimates attract considerable attention from policy-makers, donors and development organisations. Without analyses that highlight the role of informal employment in actually reducing poverty, the perception will remain that informal employment is not a viable solution to poverty reduction because, by its very nature, it is low paid or has low productivity and does not offer social and legal protection. However, if policy-makers understand the importance of earnings from informal employment to keeping many workers and their households out of poverty, policies concerned with informal employment might look quite different. Measuring the contribution of informal earnings towards national development goals, such as the poverty headcount, is one way to make this connection more tangible and relevant to policy.

Data constraints are a key problem, however, since many countries do not capture data on total household income (in order to measure income poverty) and status in employment (e.g., from Labour Force Surveys) in the same national survey. A clear recommendation which stems from this research is that, as countries work towards developing comparable indicators of working poverty (Ostermeier et al. 2015), they should also strive to collect data that highlights the impact of informal employment on national poverty rates.

Notwithstanding these existing data constraints, reducing working poverty in the informal economy is directly related to meeting three of the Sustainable Development Goals (SDGs) (UNDP n.d.). Since working poverty is a central feature of overall income poverty in most developing countries, the goals of reducing income poverty (SDG 1) and achieving decent work for all (SDG 8) cannot be met without addressing the challenges faced by informal workers in pursuing their livelihoods. Moreover, since women who work in the informal economy are more likely to be in jobs which are the most vulnerable (ILO 2018a), protecting earnings in the informal economy is a crucial strategy to achieve gender equality (SDG 5).

\section{Acknowledgements}

This research was funded by the Research Project on Employment, Income Distribution and Inclusive Growth (REDI $3 \times 3$ ). This chapter is based on a chapter in an edited volume: F.C.N Fourie and C. Skinner (eds) (2018) The South African Informal Sector: Creating Jobs, Reducing Poverty. Cape Town: Human Sciences Research Council Press. The edited volume is the result of the REDI $3 \times 3$ project (www.redi3x3.org), which was based in the Southern Africa Labour and Development Research Unit (SALDRU) at the University of Cape Town and funded by the South African National Treasury. 